\title{
EL COMERCIO EXTERIOR, ACTIVIDAD SINGULAR Y RETO ESPACIAL
}

\author{
Luis SILVAN SADA \\ Departamento de Geografía y Ordenación del Territorio \\ Universidad de Zaragoza
}

\begin{abstract}
Resumen: El comercio exterior es hoy una actividad humana dinámica y compleja que forma un enjambre de relaciones económicas entre regiones naturales y político-económicas diversas, de recursos y necesidades complementarios. Su notorio crecimiento a nivel mundial y regional no oculta sensibles desigualdades internas, ya que la movilidad contemporánea de los factores productivos afecta también a las actividades comerciales, modificando sobre el espacio global, regional y estatal la cuantía, naturaleza y dirección de los intercambios.
\end{abstract}

Palabras clave: Comercio exterior, ventaja comparativa, división internacional del trabajo (DIT), intercambio desigual, Norte-Sur, comercio cruzado, empresa transnacional (ETN), comercio intraindustrial, liberalización comercial, Organización Mundial del Comercio (OMC), proteccionismo comercial, asociación económica regional, países desarrollados (PD), países en desarrollo $(\mathrm{PED})$, países en transición (PET).

Abstract: Foreing trade is now a dynamic and complex human activity that builds a net of economic relations between different natural and politicaleconomic areas of complementary needs and resources. Although its important growing in all universal and regional levels, there are important internal inequalities, due to the contemporary movility of productif factors has an effect on. commercial activities too, modifying over global, regional and state space the quantity, nature and direction of interchanges.

Key words: foreing trade, comparative advantage, international division of labour, unequal interchange, North-South, crossed trade, transnational company, intraindustrial trade, trading liberalization, World Trade Organization, trading protectionism, regional economic asociation, developed countries, developing countries, transition countries. 


\section{LA PERSPECTIVA GEOGRAFICA DEL COMERCIO EXTERIOR}

El comercio exterior actual es una actividad humana destacable por el importante crecimiento, difusión y cambio estructural experimentado en pocas décadas, así como por sus peculiares relaciones son el espacio.

Antiguo como la humanidad, la actividad comercial se difunde a partir del descubrimiento-colonización de nuevas tierras, y de los asentamientos urbanos; hechos que permite trasvasar recursos entre distintos espacios, así como concentrardiversificar las actividades humanas.

Sin embargo, su espectacular crecimiento y ecumenismo contemporáneos tienen que ver -sobre todo- con el desarrollo humano, que aumenta y diversifica las necesidades y consumos individuales y sociales; así como con el progreso informático y las telecomunicaciones, que al reducir el espacio-tiempo aproximan y difunden la actividad comercial entre los espacios terrestres y sus agentes. El panorama se complica -además- con el protagonismo comercial logrado -junto a los entes estatales, empresas y particulares- por nuevos y poderosos agentes de intercambio: las asociaciones económicas supranacionales y las empresas transnacionales (ETN).

Por tratarse de una actividad-puente entre productores y consumidores alejados entre sí, el comercio exterior implica el espacio de forma diferente a las actividades productivas agraria e industrial. En efecto, para intercambiar bienes, recursos y manufacturas, y prestar sus servicios, las instituciones o personas relacionadas precisan disponer tanto de unas estructuras inscritas sobre el espacio: centros y canales comerciales, redes de transporte; como de una regulación nacional o supranacional específica para cada tiempo y lugar.

De ahí que el comercio exterior provoque unas relaciones socioespaciales complejas en respuesta a las distintas situaciones, distancias, bienes y servicios a intercambiar, los medios de transporte necesarios o utilizados, y las consecuencias políticas, económicas, sociales y ambientales implicadas a nivel local, nacional o supranacional.

Ahora bien, y como sucede con otras manifestaciones geográficas, los procesos y estructuras comerciales se reparten desigualmente sobre la superficie de la Tierra. Aun tratándose de una actividad ecuménica, sólo un reducido grupo de países son grandes promotores y beneficiarios del comercio exterior, mientras que la mayoría de éstos reciben de él beneficios menores e irregulares. A pesar de semejante diferenciación geográfica, todos los países -sean éstos desarrollados (PD), en desarrollo (PED), del Este o en transición (PT)- se sienten requeridos por el comercio, e intercambian sus recursos y productos propios por bienes, técnicas o capitales externos. 


\section{RELACIONES Y PROCESOS}

Ya interpretado como flujo de mercancías desde los productores a los consumidores de distintos países, como conjunto agregado de flujos de una o más mercancías o entre una o más economias estatales (JOHNSTON et al, 1987), el comercio exterior constituye la última fase del proceso productivo en sentido amplio: aquélla que lleva la mercancía o servicio al consumidor final situado en un espacio político-económico distinto.

Esta actividad interespacial es de doble sentido -importaciones y exportaciones- y pretende autocompensarse dentro de cada espacio político-económico, si bien ofrecen mayor interés y expresividad las primeras ${ }^{1}$, como manifestaciones de comercio general o de comercio especial ${ }^{2}$, pero siempre con su organización específica y un grado de regulación-liberalización variables para cada tiempo y lugar ${ }^{3}$.

Además, el comercio exterior distingue dos grandes tipos de flujos: bienes o mercancías y servicios ( $79 \%$ y $21 \%$ de su valor) ${ }^{4}$. Por su parte, los bienes pueden ser materias primas y productos transformados o manufacturas, bienes de primera necesidad o estratégicos -especialmente materias energéticas-, de volumen, peso, calidad o valor variables ${ }^{5}$. Por otra, el comercio de servicios experimenta durante las últimas décadas un notable incremento al imbricarse con las otras actividades humanas, lo cual le abre grandes expectativas ${ }^{6}$.

Si desde una perspectiva político-económica el comercio exterior se ha debatido entre la protección-cierre o liberalización-apertura de los espacios nacionales, no ha

\footnotetext{
1 Al crecer las necesidades humanas por el aumento del nivel de vida y de los mass media, el desigual reparto de los recursos terrestres, el avance de los medios de transporte, y la especialización productivacomercial.

${ }^{2}$ Normalmente el comercio total de mercancías se define como comercio general, que comprende la práctica totalidad del movimiento de entrada y salida de mercancías por las fronteras de un país o territorio. Sólo en los grandes reexportadores (Hong Kong y México) se refleja el comercio especial para no distorsionar la valoración estadística.

3 Dependiente del régimen político-económico instaurado en cada espacio, de la naturaleza del intercambio, de la coyuntura económica, de los agentes participantes, y acuerdos internacionales suscritos. El comercio responde -pues- a un régimen bilateral o multilateral, de Estado, globalizado y liberalizado, libre y de autorización previa, etc.

4 Más perceptibles por su trascendencia espacial, constituyen el comercio exterior por antonomasia: a ellos nos vamos a referir en exclusiva, puesto que la consideración de los pagos comerciales conllevaría las demás contraprestaciones exteriores (turismo, remesas de emigrantes, etc.).

5 Los datos de aduanas son preferibles a la balanza de pagos, pues comprenden todos los movimientos transfronterizos de mercancías.

${ }^{6}$ Auge actual del turismo, transporte, fletes, otros servicios, rentas de inversión, royalties e intereses. Aunque no hay acuerdo internacional para definir los que son objeto de comercio, el GATT entiende por servicios comerciales los de transporte, viajes y otros servicios y rentas del sector privado, cuya única fuente de información comparable son las estadísticas de la balanza de pagos.
} 
dejado de ser -por esa diatriba- una actividad de importancia creciente ante el desarrollo cuanti-cualitativo de la humanidad.

Para la Geografía representa una actividad humana fundamental, cuyos resultados parecen contradictorios según la escala espacial y perspectiva que empleemos en su análisis. De hecho, tanto integra el modo de vida de ciertos países, grupos o individuos, como contribuye a la prosperidad socioeconómica general; que genera un intercambio desigual entre PD y PED, como repercusiones específicas para los individuos agentes o pacientes del mismo.

El comercio internacional contemporáneo -señalan THOMAN y CONKLING (1972, a) está fundamentado en siglos de experiencia y deriva de estimulos y móviles definidos. Aunque razones generales de sentido común lo impulsan ${ }^{7}$, el proceso difusor de la actividad y su aceleración postbélica se explican por hechos específicos como:

- la consolidación del sistema multilateral de libre comercio (GATT),

- la creación de dos zonas de libre cambio (CEE y AELC) e, inicialmente,

- un sistema de tipos de cambio fijos (Bretton Woods).

Sin embargo, las razones finales del comercio exterior son complejas, y difieren entre espacios y épocas según el tipo de intercambio y los agentes institucionales o personales implicados ${ }^{8}$. De ahí ese continuum de teorías clásicas, marxistas y neoclásicas que durante los últimos 150 años han tratado de explicarlo sin conseguirlo plenamente, suscitando su compleja dinámica espacio-temporal nuevos planteamientos teóricos sobre los espacios comerciales terrestres?.

7 Entre las que mencionamos:

-las diferencias regionales en las condiciones de producción (latitud, tierra, trabajo, capital, técnica), que permiten utilizar la ventaja comparativa en la producción y comercialización exterior de determinados bienes;

-los costes decrecientes por el incremento de la producción, su especialización y eficacia;

-las diferencias de gustos y de poder adquisitivo entre consumidores de distintos espacios productivos.

${ }^{8}$ Los Estados buscan en el comercio una vía de aumentar su poder -político, económico, fiscal- así como el bienestar de sus ciudadanos, el GATT/OMC la liberalización arancelaria y el acceso a lo mercados que acrecienten la producción y el comercio mundiales. Por otra parte, el empresario puede buscar en el exterior una ampliación de su mercado para rebajar costes o disminuir riesgos; y la empresa transnacional un beneficio diferencial (costes de factores, ventajas fiscales, etc.).

${ }^{9}$ Unos reconducen el concepto de nación como unidad activa y de poder (Mérigot y Perroux), otros realzan las diferencias entre países para explicar el comercio Norte-Sur (ventaja comparativa relativa, diferencias olvidadas, ventaja comparativa tecnológica, ciclo del producto, de la disponibilidad de bienes), o las similitudes entre ellos para el comercio Norte-Norte (demanda representativa, demanda diferencial). 


\section{VALORACION}

El comercio exterior crece, se difunde y diversifica con la revolución de los transportes y la expansión colonial del nacionalismo europeo, convirtiéndose en un medio -en principio pacífico- de actuación internacional. De la desarticulación socioeconómica ocasionada por la última guerra y el ansia por erradicar los errores del pasado arrancan los pilares institucionales donde cimentar el progreso económico y la paz entre las naciones ${ }^{10}$. Limitado tradicionalmeante a pocos países y para escasos productos, desde la segunda mitad del siglo XX la actividad se multiplica y amplía espacialmente, complicando además sus manifestaciones; es decir, estamos ante un fenómeno moderno, que por la forma como se ha producido podríamos calificar incluso deposmoderno.

El valor de las exportaciones mundiales de mercancías se ha multiplicado por 400 a lo largo del presente siglo, pasando de 10.100 millones de dólares a 4.060 .000 de dólares en 1994, más otros 1.080 millones por exportación de servicios. A pesar de esa tendencia ascendente -en especial desde los años cincuenta-, su ritmo difiere entre bloques, áreas y países, en razón del régimen político-económico, tamaño, población, renta y apertura exterior de cada uno de los espacios concernidos.

En principio, el grado de apertura comercial de cada espacio pone des manifiesto el crecimiento económico y desarrollo que ha alcanzado ${ }^{11}$. No obstante las diferencias de unos a otros, la mayor parte de los países del mundo se plantean la apertura como objetivo importante, seguido del interés público y privado por mantener y reforzar el sector ${ }^{12}$.

\footnotetext{
10 Mediante organismos de cooperación política (ONU), económica (FMI, BMRD), comercial (GATT), social (OIT) y cultural (UNESCO), completados enseguida -a una escala más próxima y operativa- por uniones económicas de carácter regional. Los logros de FMI y GATT -dos de aquellos organismos- tendrán mucho que ver en el desarrollo económico y comercial contemporáneo: la convertibilidad de las monedas por los Acuerdos de Bretton Woods y la sucesiva vigencia de los principios de multilateralidad comercial.

11 Se le asigna hoy un papel de motor del consumo de cada país, produciendo -además- otras importantes consecuencias socioeconómicas: incrementa su nivel de actividad y de vida, especializa la producción, reduce el nivel de precios, dinamiza las actividades de servicios y transporte, y genera efectos espaciales variables. La participación en el PIB, el grado de apertura y la penetración del comercio exterior son indicadores macroeconómicos básicos a nivel regional y de actividad.

12 La transformación de la demanda tiene importantes repercusiones geográficas. Así, p.e., una disminución de la exportación de productos primarios como algodón, yute, caucho natural, pieles y cueros, etc. perjudica a muchos PED, y beneficia a los PD y sus productos industriales sustitutivos. Otros productos primarios -frutas tropicales, carnes, algunos minerales, petróleo- que mejoran su situación competitiva internacional, trasladarán a todos las consecuencias del alza de precios de los crudos. Al deteriorarse la relación real de intercambio, los PED exportadores de materias primas intensifican las medidas defensivas. Por su parte los PD acompañan las políticas de reconversión o desindustrialización con medidas proteccionistas de la siderurgia, el textil, el automóvil o la agricultura, y de exenciones fiscales o tipos de interés que aislan las exportaciones de la inflación y producen otros desajustes económicos.
} 
Sin embargo, ni el tamaño ni la capacidad adquisitiva de un país explican siempre su apertura económica y comercial hacia el exterior, incluso entre PD (Fig. 1). La propensión a importar depende de hecho de la dimensión del mercado interno, de los hábitos de los consumidores, de políticas comerciales nacionales -como la sustitución de importaciones-, del equilibrio de la balanza comercial y de pagos. Incluso la estrategia comercial contemporánea propende a exportar cuanto se pueda y aceptar las importaciones sólo como contrapartida de las ventas en el exterior.

Una reflexión geográfica sobre el comercio exterior actual pretende siempre diferenciar, cuantificar y cualificar las estructuras que genera sobre la superficie terrestre. Para ello se sirve -por una parte- de indicadores como los coeficientes comercial, de exportación y de importación, la tasa de crecimiento anual, la relación de intercambio, el comercio exterior per capita, la especialización de las exportaciones, etc., que nos permiten cotejar esa actividad con los parámetros socioeconómicos básicos del espacio ${ }^{13}$; y por otra, de los sistemas de cuentas o balanzas que cada país dispone para registrar sistemáticamente las transacciones económicas anuales entre sus ciudadanos y los de otros países ${ }^{14}$.

\section{DISTRIBUCION DEL COMERCIO EXTERIOR}

El comercio exterior se singulariza hoy como una actividad de difusión ecuménica, de rápido crecimiento, pero con notables diferencias interespaciales e importantes cambios en su reparto y composición ${ }^{15}$. La actividad comercial sobre la

\footnotetext{
13 El coeficiente de exportación relacionando las ventas con el PIB, indica la apertura de un país hacia el exterior, mientras que el coeficiente de importación (también respecto al PIB), la dependencia o penetración de los productos extranjeros. Por último, una curva de Lorenz permite expresar el grado de especialización de las exportaciones.

14 Si es posible, la compensación se realiza dentro de la misma balanza comercial, saldo resultante entre la importación-exportación de bienes (comercio visible); con los intercambios de servicios (comercio invisible) constituye la balanza de bienes y servicios. A menudo requiere la ayuda de las transferencias (balanza por cuenta corriente) o de los capitales a largo plazo (balanza básica). La situación de la balanza comercial permite conocer la capacidad exportadora del país: para equilibrarla basta una cobertura del $90-93 \%$ entre importaciones-exportaciones, por la valoración cif y fob de uno y otro flujo; pero a menudo las importaciones sobrepasan a las exportaciones si se generan divisas por otros conceptos de la balanza de pagos (turismo, emigrantes, capital y préstamos). El saldo resultante dependerá -además- de otras macromagnitudes económicas internas, de los precios internacionales y la relación de intercambio. En la realidad algunos países han obtenido cuantiosos excedentes dinerarios de los petrodólares y el alza del precio de los crudos -Eurobonos y Eurodólares-, pero son bastantes más los endeudados por culpa de la balanza de pagos.

15 En efecto, su trascendencia geográfica se manifiesta en:

-la aceleración de su crecimiento medio en volúmen (del 5,1\% en la última década) y valor, siempre por encima del experimentado por la producción;

-las importantes diferencias regionales y nacionales, a favor del Norte, países desarrollados, de tradición industrial y urbanización, de las empresas transnacionales, del comercio intrarregional;
} 
superficie terrestre diferencia unos espacios de otros, realizándose sus flujos en direcciones y con estructuras específicas para cada nivel regional o nacional.

\section{Importancia de los espacios comerciales}

E1 irregular reparto sobre la Tierra de los factores productivos, o su diferente aprovechamiento por los grupos humanos, genera un intercambio desigual de bienes o servicios, constatado sobre escalas y agrupaciones diversas:

a) La división del mundo en tres espacios político-económicos -cómoda y expresiva- ha perdido vigencia con la transición político-económica del mundo socialista. Esos Tres Mundos concentraban respectivamente -al final de los años ochenta- el $70 \%, 10 \%$ y $20 \%$ del comercio mundial.

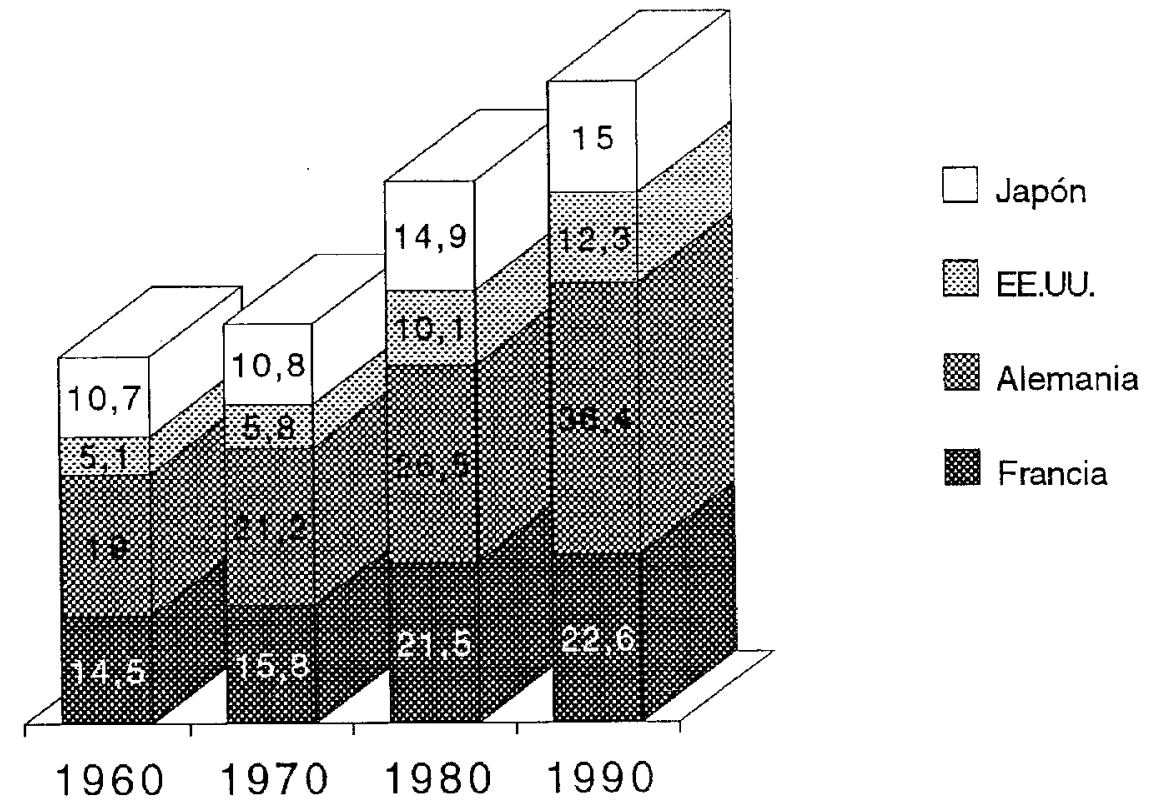

Figura 1.- Apertura comercial de algunos países desarrollados entre 1960 y 1990. Datos porcentuales.

\footnotetext{
-la nueva distribución internacional del trabajo, con Nuevos Países Productores y Exportadores, especialmente en Asia y Latinoamérica, la incorporación decidida del comercio chino y desigual de los países emergentes del bloque comunista; y por último,

-la expansión de los servicios comerciales (21\% del valor de las exportaciones mundiales en 1992), que puede interpretarse como actividad sustitutiva para los espacios "perdedores" en la nueva distribución mundial del comercio.
} 
b) El reparto por continentes o regiones subcontinentales (Fig. 2) expresa diferencias en nivel de desarrollo y poblacional, tejido socioeconómico, accesibilidad y vertebración del territorio. Europa figura a la cabeza -en comercio total e internopor sus agrupaciones económicas regionales (50,23\%), seguida por Asia $(29,29 \%)$ y América $(20,09 \%)$, en ambos con ligero dominio del externo sobre el interno. Africa sólo realiza el 2,38\% del comercio total, casi todo con el exterior.

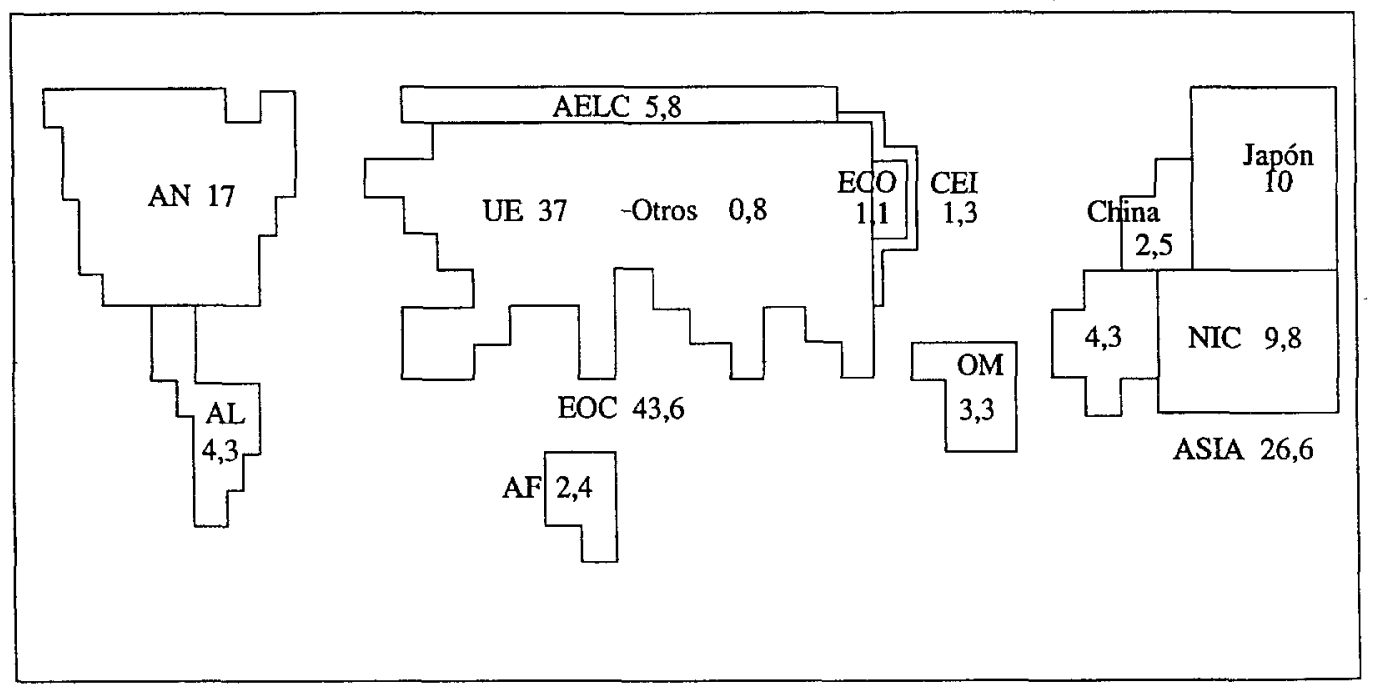

Figura 2.- Importancia del comercio exterior por grandes regiones '(1992). Datos porcentuales.

c) Las cuatro grandes regiones desarrolladas (Europa occidental, América del Norte, Japón y Europa del Este) concentran en sí mismas más del 60\% del comercio exterior, frente al 5\% de las cuatro en desarrollo (Africa, América Latina, Oriente Medio y Extremo Oriente); el 35\% restante corresponde al comercio intrarregional.

Así pues, un dominio abrumador y creciente del comercio Norte-Norte por proximidad y ventaja comparativa, frente a unos flujos Norte-Sur sostenidos por complementariedad y viejos lazos coloniales, mientras que los insignificantes intercambios Sur-Sur se explican por similaridad y aislamiento espaciales. 
d) El comercio interno de las asociaciones de cooperación o integración económica regional se estima en un $60 \%$ del total, siendo su contribución al comercio exterior menor y muy desigual entre ellas.

e) El comercio exterior de las empresas transnacionales es tan importante como poco transparente al ser intraindustrial, y la apreciación de su cuantía varía del 5 al $40 \%$ del total (5-10\% para el FMI y $10-5 \%$ para el GATT) ${ }^{16}$.

f) El comercio acogido a la OMC tras la Ronda Uruguay del GATT (con 126 países miembros, e inclusión de la agricultura y algunos servicios) supone en teoría el 85\% del total, pero con frecuentes excepciones e incumplimientos.

g) El comercio mundial se concentra en las grandes potencias comerciales o espacios económicos integrados, pues los intercambios de Estados Unidos, Comunidad Europea y Japón totalizaron en 19922.400 miles de millones de dólares, es decir el $61^{\prime} 4 \%$ del valor total ${ }^{17}$. A partir de 1993 el Mercado Unico de la UE la sitúa en el podium comercial del mundo, sin contar su mercado interior.

h) Ello no impide que Nuevos Países Exportadores irrumpan con fuerza en el comercio mundial (Tabla 1), sobre todo los países emergentes de Asia (dragones y tigres), América Latina (México) o de Europa Centro-Oriental ${ }^{18}$.

i) Mientras, los $P E D$ realizan sólo el 3'3\% del comercio internaciona1 ${ }^{19}$.

\section{Direcciones de intercambio}

La diferenciación espacial se manifiesta también en la dirección seguida por los flujos comerciales, especialmente las exportaciones (Tabla 2).

\footnotetext{
16 Una muestra de ello, en 1990 protagonizaban el 63,2\% de las exportaciones de los Estados Unidos y el $433 \%$ de sus importaciones.

17 Ese año la CE situaba a seis de sus miembros entre los diez países principales exportadores e importadores en el comercio mundial de mercancías: Alemania $\left(2^{\circ}\right)$, Francia $\left(4^{\circ}\right)$, Reino Unido $\left(5^{\circ}\right)$, Italia $\left(6^{\circ}\right)$, Países Bajos $\left(7^{\circ}\right)$ y Bélgica-Luxemburgo $\left(9^{\prime \prime}\right)$.

${ }^{18}$ Son los países de más rápido crecimiento del momento (tasas del $10^{\prime} 5 \%$ y $8 \%$ para las dos primeras regiones en 1993). Seis países de Asia Oriental (Japón aparte) aparecen entre los veinte mayores exportadores e importadores del mundo, destacando el comercio de reexportación en Hon Kong y China.

19 Tras un pasado reciente regresivo, crecen -en general- desde el inicio de los años 90 gracias a la contribución de políticas internas, capital extranjero o tipo de interés internacional. Hoy las perspectivas son menos favorables para el Africa subsahariana y Oriente Medio, mientras que países como Malasia, Tailandia o Chile -otrora fuertemente dependientes de productos primarios- incrementan su productividad al diversificar sus productos y exportaciones.
} 
Europa Occidental realiza el 72 '9\% de ellas consigo misma, dirigiéndo las restantes sobre todo a Asia y América del Norte. En Asia las internas son aún el 45\%1\%, y sus principales destinos externos América del Norte y Europa Occidental. América del Norte interioriza el 33,3\% de su comercio, y dirige el exterior sobre todo hacia Asia y Europa Occidental. El comercio intrarregional de las restantes regiones es muy escaso, contrariamente al interregional ${ }^{20}$.

Las balanzas comerciales entre los Estados Unidos y la Comunidad Europea se mantienen equilibradas, mientras que las de ambos con Japón padecen un desequilibrio crónico, debido tanto a la estructura comercial como a unas políticas comerciales muy diferentes ${ }^{21}$.

Los flujos comerciales del Norte con el Sur son peculiares. Alrededor de cada polo se configuran zonas de predominio comercial de los países industriales próximos: Europa Occidental sobre espacios ex-coloniales de su entorno, es decir, países mediterráneos, Africa del Norte y Oriente Medio, ya en competencia con Europa Central y Oriental; Norteamérica ejerce todavía mayor atracción sobre el área caribeña; y Japón ensancha con fuerza su esfera de influencia por el Extremo Oriente y Sudeste de Asia. Con la distancia los tres focos disputan su influencia: la presencia de Europa en Africa es contestada por Estados Unidos y Japón, mientras que Estados Unidos está presente en América del Sur, entre la huella europea y la sombra japonesa.

Por tanto, el comercio mundial tiene una estructura general bastante sencilla: tres grandes haces de flujos relativamente independientes y dispuestos según un eje meridiano, convergen hacia los tres polos de desarrollo de América del Norte, Europa y Japón, focos que mantienen entre sí intercambios muy activos; mientras que con el resto del mundo -es decir el Sur- el intercambio es escaso, desigual e insolidario.

\section{Naturaleza y contenido de los intercambios}

El comercio mundial ofrece en cada momento una naturaleza y contenido característicos. Tradicionalmente se insistía sobre los aspectos espaciales de los grandes productos; pero la nueva división internacional del trabajo y la participación

20 Parecido en Europa Centro-oriental y América Latina (18'5\% y 17'2\%, respectivamente), que exportan sobre todo a Europa Occidental $\left(61^{\prime} 9 \%\right.$ ) la primera, y a América del Norte (46.8\%) y Europa Occidental (20'3\%), la segunda. También el de Oriente Medio y Africa (7'7\% y 6'7\%), dirigiendo el interregional hacia Asia $\left(41^{\prime} 6 \%\right)$ y Europa Occidental $(26,5 \%)$ en el primer caso, y-sobre todo- a Europa Occidental $(56,3 \%)$ en el segundo.

${ }^{21}$ Sus índices de cobertura respectivos son del $80^{\prime} 8 \%, 95,2 \%$ y $145 \%$; las manufacturas representan el $95^{\prime} 9 \%$ de las exportaciones del Japón, el $28,4 \%$ con destino a Estados Unidos y el $18 \%$ \% a la CE, mientras que sólo importa de ellos el $226 \%$ y $13{ }^{\prime} 4 \%$. 
creciente de los servicios en el tráfico internacional alteran la estabilidad y concreción de aquellas distribuciones.

Un primer rasgo a destacar en el comercio exterior actual es la progresiva transformación de la naturaleza de los intercambios: en 1992 el valor de las exportaciones mundiales correspondía en un $79 \%$ a las mercancías y en el $21 \%$ a los servicios $^{22}$.

Una segunda apreciación se refiere a la participación creciente de las manufacturas en la composición de los bienes o mercancías comerciadas (Tabla 3): un $72{ }^{\prime} 8 \%$ de éstas, que puede llegar al 95 '9\% de la exportación en el caso paradigmático del Japón; auge debido tanto al aumento del consumo con el desarrollo humano, como a la aparición de Nuevos Productores y Exportadores.

En cambio, el comercio mundial de productos primarios -agropecuarios $\mathrm{y}$ materias extractivas- ha crecido mucho más lentamente que el PIB mundial, participando cada uno con el 12 ' $\%$ de las exportaciones totales. Su irregularidad productiva, los productos de sustitución o los intereses económicos internacionales han contribuído a su contínua pérdida de valor y a agravar la relación de intercambio de muchos PED: 29 de los 49 países del Africa.

Tiene interés geográfico la clasificación de los países según algunos parámetros económicos e indicadores comerciales, aspectos que reflejan su situación en el concierto del espacio-mundo.

a) El volumen de ingresos de los dos centenares de países establece las posibilidades teóricas de practicar la actividad comercial internacional, distinguiéndose 56 PMD con ingreso bajo, 70 PED de ingreso mediano bajo, 43 PED de ingreso mediano alto, y -por encima- sólo $38 \mathrm{PD}$ de ingreso alto ${ }^{23}$.

b) El endeudamiento dificulta la actividad comercial. El Banco Mundial registra 53 países severamente endeudados 24,30 moderadamente endeudados y 66 menos endeudados; a parte los 21 países de la OCDE y 18 fuera de cómputo.

\footnotetext{
22 Si bien la dificultad de medirlos estadísticamente introduce un sesgo por defecto. El ascenso de éstos y su imbricación con los bienes manufacturados suscita el interés de los PD por incluírlos en la liberalización del GATT, que frena de momento el temor de los PED a un incremento del intercambio desigual.

23 Hasta 675, 2695, 8355 dólares per capita, o más, respectivamente.

24 Con un coeficiente de deuda/PIB $>50 \%$, una deuda/exportaciones $>275 \%$, un servicio de la deuda/exportaciones $>30 \%$ y un pago de intereses / exportaciones $>20 \%$.
} 


\begin{tabular}{|l|c|c|c|c|c|c|}
\hline \multicolumn{1}{|c|}{ Año } & \multicolumn{2}{c|}{1955} & \multicolumn{2}{c|}{1973} & \multicolumn{2}{c|}{1990} \\
\hline \multicolumn{1}{|c|}{ País } & $\%$ & $\mathrm{~N}^{2}$ & $\%$ & $\mathrm{~N}^{2}$ & $\%$ & $\mathrm{~N}^{2}$ \\
\hline Alemania & 7,7 & 3 & 13,2 & 2 & 11,4 & 1 \\
\hline Estados Unidos & 19,0 & 1 & 13,6 & 1 & 11,3 & 2 \\
\hline Japón & 2.4 & 8 & 7.1 & 3 & 8,3 & 3 \\
\hline Francia & 6,0 & 4 & 6,9 & 4 & 6,2 & 4 \\
\hline Reino Unido & 9,6 & 2 & 5,9 & 5 & 5,3 & 5 \\
\hline Hong Kong & 0,5 & - & 1,0 & 25 & 2,4 & 11 \\
\hline Taiwan & 0,1 & - & 0,9 & 28 & 1,9 & 12 \\
\hline Corea & 0,0 & - & 0,6 & 38 & 1,9 & 13 \\
\hline Singapur & 1,3 & - & 0,7 & 34 & 1,5 & 18 \\
\hline
\end{tabular}

Tabla 1. - Viejas y nuevas potencias comerciales (GATT, 1993).

\begin{tabular}{|l|r|r|r|r|r|r|}
\hline \multicolumn{1}{|c|}{ Comercio } & \multicolumn{3}{c|}{ intrarregional } & \multicolumn{3}{c|}{ extrarregional } \\
\hline \multicolumn{1}{|c|}{ Regiones } & Valor m.m. & \% región & \% mundo & Valor m.m. & \% región & \% mundo \\
\hline Europa Occidental & 1230 & 72,9 & 34,2 & 457 & 27,0 & 12,7 \\
\hline Asia & 394 & 45,1 & 10,9 & 478 & 54,8 & 13,2 \\
\hline América del Norte & 195 & 33,3 & 5,4 & 389 & 66,6 & 10,8 \\
\hline América Latina & 26 & 17,2 & 0,7 & 122 & 82,7 & 3,3 \\
\hline Oriente Medio & 10 & 7,7 & 0,2 & 114 & 92,1 & 3,1 \\
\hline Europa C.-Oriental & 17 & 18,5 & 0,4 & 75 & 81,5 & 2,0 \\
\hline Africa & 6 & 6,7 & 0,1 & 83 & 93,6 & 2,4 \\
\hline \multicolumn{1}{|c|}{ Total mundo } & 1878 & 100,0 & 52,2 & 1718 & 100,0 & 47,7 \\
\hline
\end{tabular}

Tabla 2.- Comercio exterior de mercancías (GATT, 1993).

\begin{tabular}{|l|c|c|c|c|c|c|}
\hline \multicolumn{2}{c|}{ Productos } & \multicolumn{2}{c|}{ agropecuarios } & \multicolumn{2}{c|}{ extractivos } & \multicolumn{2}{c|}{ manufacturados } \\
\hline \multicolumn{1}{|c|}{ Regiones } & Export. & Import. & Export. & Import. & Export. & Import. \\
\hline Europa occidental & 46,8 & 50,5 & 25,2 & 42,9 & 51,1 & 47,5 \\
\hline América del Norte & 19,6 & 11,1 & 10,1 & 17,0 & 15,8 & 19,4 \\
\hline Asia & 19,2 & 22,6 & 14,7 & 28,3 & 27,2 & 19,2 \\
\hline América Latina & 8,5 & 4,3 & 9,6 & 3,8 & 2,6 & 4,8 \\
\hline Europa C.-Oriental & 2,6 & 4,3 & 7,1 & 2,3 & 1,7 & 2,4 \\
\hline Oriente Medio & 0,9 & 3,4 & 21,9 & 1,7 & 0,8 & 3,6 \\
\hline Africa & 3,4 & 3,6 & 11,3 & 2,2 & 0,7 & 2,5 \\
\hline
\end{tabular}

Tabla 3.- Estructura regional de la exportación, en \% (GATT, 1993). 
c) El comercio per capita establece otro principio de diferenciación entre espacios: con un valor medio mundial 657 dólares, asciende a 3395 en los países de alto ingreso y desciende a 55 dólares en los de bajo ingreso.

d) El carácter comercial distingue países exportadores netos (Japón, Noruega, Alemania, Dinamarca, Irlanda, Canadá, Brasil, Indonesia, China, Nigeria), reexportadores (Hong Kong, México), importadores netos (Estados Unidos, Reino Unido, España, Grecia, Portugal, Turquía, Marruecos, Filipinas, India, Hong Kong, México), abiertos (coeficiente de exportación por encima del 25\%: Países Bajos, 43.6\%, Bélgica, 56' $2 \%$, Irlanda 65'4\%) o cerrados (por debajo del 15\%: Estados Unidos, 7\%, Japón, 9'2\%, España, 11'1\%), equilibrados (en general los PD) o desequilibrados (frecuentemente los PED). Por categorias de exportación 32 países son exportadores de manufacturas, 54 de productos primarios, 17 de combustibles, 45 de servicios, 45 diversificados, no clasificándose 20 países.

\section{EL RETO ESPACIAL DEL COMERCIO EXTERIOR}

Así pues, el comercio exterior aparece hoy como actividad singular, animadora de la actividad humana y origen de diversificación espacial, planteándonos -de cara a su futuro- el reto de armonizar los intereses contradictorios entre espacios desarrollados y subdesarrollados, nacionales y transnacionales, cerrados y abiertos, explotados de forma indiscriminada o sostenible. Por eso concluímos señalando algunos de los desafíos espaciales que esta actividad plantea:

$1^{\circ}$. El nivel de desarrollo de cada espacio incide en la densidad, diversificación, especialización, reversibilidad y equilibrio de sus relaciones comerciales, y distingue los intercambios Norte-Norte, Norte-Sur y Sur-Sur.

$2^{\circ}$. La importancia creciente de los intercambios cruzados de manufacturas y servicios entre $P D$ se basa en unas condiciones productivas similares, con la ventaja comparativa de un mercado ampliado como el de la UE y la AELC.

$3^{\circ}$. El intercambio desigual entre PD -productores de manufacturas y servicios- $y$ $P E D$-suministradores de alimentos y minerales- genera permanente inestabilidad en los mercados de materias primas y tecnología, que -no obstante lucrarse de unas condiciones laborales más bajas- puede hacerse insostenible.

$4^{\circ}$. El crecimiento y difusión de las ETN -como productoras sin fronteras- las convierte en agentes de primer orden del comercio exteriorcautivo, intrasocial o 
intraindustrial; comercio transnacional que se materializa por el empleo cada vez más frecuente de formas de compensación copiadas de los Estados.

$5^{\circ}$. La aplicación del sistema GATT/OMC encuentra dificultades para incorporar el comercio de servicios, pero las excepciones que prevé a favor de agrupaciones regionales, PED, PET y acuerdos de autolimitación -junto al cuantioso comercio de compensación y transnacional- pueden acabar desvirtuando de facto los fundamentos liberalizadores que propugna.

$6^{\circ}$. y último: la mundialización de las actividades productivas y el crecimiento deseable del comercio exterior exigen hoy su compatibilidad con el medio ambiente, razón por la que la nueva OMC introduce -al efecto- el principio del desarrollo sostenible respecto a la utilización óptima de los recursos, y la necesidad de una protección medioambiental compatible con el nivel de desarrollo económico de cada país.

Pero si preservar el medio ambiente es ya una cuestión planetaria -como lo sea la actividad económica o el desarrollo humano-, se hace misión imposible con la inercia del intercambio desigual a favor de la sociedad del bienestar. Por eso convendría aprender la lección de nuestro reciente pasado, pues -como nos recuerda el Banco Mundial (1991, 127)- los países que hoy dia son industriales prosperaron gracias al comercio. No se debe escatimar ningún esfuerzo para que los países en desarrollo puedan seguir el mismo camino que lleva al progreso. Así pues, un Nuevo Orden Económico Internacional requiere cambios substanciales que propicien a nivel planetario un intercambio de bienes y servicios socialmente más justo y en equilibrio con el medio ambiente.

\section{BIBLIOGRAFIA}

Acuerdo General sobre Aranceles Aduaneros y Comercio (1993): El Comercio Internacional 1993. Estadísticas., GATT . 120 p. Ginebra.

ANDERSON, K. y BLACKHURST, R. Dirs. (1992): El comercio mundial y el medio ambiente. Mundi-Prensa, 300 p. Madrid.

ANDREFF, W. (1987): Las multinacionales. Repères, Paris.

Banco Mundial (1994): Las perspectivas económicas globales y los Países en Desarrollo, 1994. Washington, D.C.

BEAUjEU-GARNIER, J. et DELOBEZ, A. (1977): Géographie du commerce. Masson, Paris. 
CANALS, J. (1993): La nueva economía global. Expansión DEUSTO, 314 p. Bilbao.

CARREAU, D., FLORY, Th. et JULLLARD, P. (1990): Droit international économique. LGDJ, 725 p. París.

DEZERT, B. et WACKERMANN, G. (1991): La nouvelle Organisation des échanges. Dossiers des Images économiques du monde. Sedes, 234 p. París.

GRANELL, F. (1989): La exportación y los mercados internacionales. Hispano Europea, 455 p. Barcelona.

OCDE: Statistics of Foreing Trade.

PAMPILLON, R. (1993): Análisis económico de países. Teoría y casos de politica económica. McGraw-Hill, 243 p. Madrid.

SANDRETTO, R. (1989): Le commerce international. Colin, 192 p. París.

SCHNEIDER, B. (1995): El escándalo y la vergüenza de la pobreza y el subdesarrollo. Informe al Club de Roma. Galaxia Gutemberg/Círculo. 236 p.

SEBASTIAN, L. DE (1994): Mundo rico, mundo pobre. Pobreza y solidaridad en el mundo de hoy. Círculo de Lectores, 255 p. Barcelona.

THOMAN, R.S. y CONKLING, E.C. (1972) Geografía del comercio internacional. Vicens-Vives, 250 p. Barcelona. 